\title{
Individual and Psychological Characteristics of Medical University Students with Risk Appetite
}

\author{
Viktor Zaplavnyi ${ }^{1}$, Amir Amirov $^{1}$, Aliia Kubekova ${ }^{1},{ }^{*}$ Veronika Mamina ${ }^{1}$ \\ ${ }^{1}$ Astrakhan State Medical University of the Ministry of Health of Russia, Russia \\ *Email: alya_kubekova@mail.ru
}

\begin{abstract}
The article analyses the individual psychological characteristics of medical university students with different levels of risk appetite. Personal characteristics were determined using the D. Keirsey method (adapted by B.V. Ovchinnikov, K.V. Pavlov, I.M. Vladimirova, E.P. Ilyin); the risk propensity was revealed using the Schubert method (PSK). As per the risk appetite questionnaire, students were divided into three groups: high, medium, and low-risk appetite. The authors found that the leading characteristics of the personality of students with a high propensity to take risks are extraversion, intuition, ethics of emotions, rationality (ENFJ). Statistical processing of the results was carried out using the Spearman's rank correlation coefficient for correlation analysis. Data processed using SPSS 21.0 software. The obtained research data can be used in the work of practical psychologists of educational institutions for career guidance activities for students graduating from a medical university.
\end{abstract}

Keywords: Medical students, Pandemic COVID-19, Risk appetite, Personality traits, Extraversion, Correlation analysis.

\section{INTRODUCTION}

In the study of individual psychological characteristics of a person, such psychological characteristics as a propensity to take risks are essential. American psychologists M. Tsuang, M. Bohr and J. Fleming consider the propensity to take risks as a kind of psychological defence [1, p.538-546]. In Germany in the 1950s-1960s for the first time, theoretical premises were formulated about the propensity to take risks as a personal characteristic. The relationship of personality traits was established, including the propensity to take risks on the adaptation process of first-year students. Yanykhbash A.V. [3, p.19] and E.Yu. Mandrikova [4, p.21] also considered the connection between the propensity to commit dangerous acts with psychological characteristics of the personality. As of now, there are no data on the relationship between the propensity to take risks and the leading activity of the individual, his social and professional status and the overall social development situation. Kogan N., Wallach M. adhered to the position that a person who seeks to manifest risky behaviour in one situation will seek to take risks in other situations [5, p.75-84.]. According to T.V. Kornilova, two erratic behaviours are studied: risk with positive consequences and risks with an unpleasant outcome, such as reckless driving, smoking or risky sexual behaviour [6, p.98]. According to N.V. Moskvina, the risk can "be either motivated, adequate, or unmotivated, inadequate" and those risk lovers can be viewed as either "heroes" or "fools" [7, p.45].

Chastoedova E.V., Istomina M.S., Zlokazova M.V. $[8, \mathrm{p} .65]$ in their study found that a third of medical students have a high level of seeking new sensations, which means a person's willingness to take risks and the justification of this willingness. In the work of Mukhamadeev R.I., Mukhamadeev I.G. [9, p.18] the relationship between the level of risk appetite and the year of study of students is shown.

An insufficient number of studies of personality traits and propensity to take risks in medical students, as well as the correlation between these indicators, determined the relevance of this study. In practical terms, the relevance lies in need to develop recommendations in the activities of practical psychologists of educational 
institutions for career guidance activities for students graduating from a medical university.

The purpose of the study is to research the individual psychological characteristics of students of a medical university with a tendency to take risks.

\section{MATERIALS AND RESEARCH METHODS}

The experimental study was carried out in October 2020 at the Department of Psychology and Pedagogy of the Federal State Budgetary Educational Institution of Higher Education "Astrakhan State Medical University" of the Ministry of Health of Russia (Astrakhan). In the psychodiagnostic examination, 60 students of a medical university in the 5th year of the medical and paediatric faculty took part. Personal characteristics were determined using 1) D. Keirsey's method, which determines the type of temperament and stable personality characteristics (adapted by B.V. Ovchinnikov, K.V. Pavlov, I.M. Vladimirova, E.P. Ilyin). The Keirsey's questionnaire is a temperament assessment technique based on the works of C.G. Jung and I. Myers-Briggs. The questionnaire contains four bipolar scales reflecting the content of eight psychological factors of temperament (within the framework of the theoretical concepts of C.G. Jung and his followers): extraversion-introversion (E-I); sensationintuition (S-N); thinking-feeling (T-F); judgingperceiving (J-P) (planning-impulsivity); 2) risk appetite was revealed using the Schubert method (PSK). The overall test score is given on a continuous scale as the deviation from the mean. Positive responses indicate a risk appetite. Test value: from -50 to +50 points to risk is directly proportional to the number of mistakes made [10, p. 189]. Statistical processing of the results was carried out using Spearman's rank correlation coefficient for correlation analysis. Data processed using SPSS 21.0 software. The results were considered statistically significant at $\mathrm{p}<0.05$. To obtain comparable results, the psychological examination was carried out under conditions that were the same for all students of the medical university. The research results are presented in figures and table.

\section{THE DISCUSSION OF THE RESULTS}

According to the results of test diagnostics with the PSK questionnaire, A.M. Schubert "Diagnostics of the level of personal readiness to take risks" three groups of students of a medical university with a high, medium and low propensity to take risks were identified (figure 1). We found that $27.6 \%$ (13 people) of medical students have a high propensity to take risks, which means that they are ready to take risks, being in an uncertain situation, not to be afraid of losing existing material (spiritual) benefits for the sake of something greater.

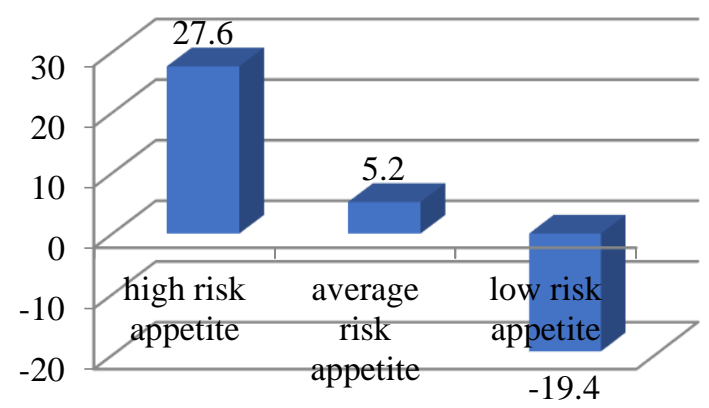

Figure 1 Average values of the level of risk appetite among medical students according to the method of A.M. Schubert (compiled by the authors based on the research results).

The indicator of the average propensity to take risks was found in $5.2 \%$ of students (30 people). A low propensity to take risks was found in $19.4 \%$ (17 people) of medical students, which indicates their cautious behaviour; they avoid danger, have trouble in situations of uncertainty and are unable to make decisions on their own.

The following technique is aimed at assessing the type of temperament and stable personality characteristics. The average indicators were found according to D. Keirsey's test (adapted by B.V. Ovchinnikov, K.V. Pavlov, I.M. Vladimirova, E.P. Ilyin) in three groups as a result of interpretation of the data obtained (figure 2).

According to the Keirsey questionnaire results, among students of the first group with a high propensity to take risks, such an indicator as extraversion prevails $(1.5 \%)$. People of the extraverted type tend to immediately and directly respond to external stimuli. Their psychic energy has a pronounced focus on the environment and external objects. Extroverts get energy from their interactions with people. They are always ready to continue communication. They also have a dominant intuition $(1.4 \%)$. Such people get to know the world using intuition. In the thinking-feeling dyad, the students with a tendency to take risks are dominated by feeling (1.4\%). Among students of the first group in the judging-perceiving dyad, judging predominates (1.2\%).

They strive to make a particular decision as early as possible and then act within the framework of a specific plan, consistently working out intermediate stages on the way to achieving a good goal. Thus, students with a tendency to take risks have a psychological portrait of ENFJ "Educator": a humanistic leader, sociable, attentive to the feelings of other people, an exemplary parent; impatient with routine and monotonous activities; able to distribute roles in the group. 
Table 1. The results of the correlation analysis between personality traits and indicators of risk appetite in medical students

\begin{tabular}{|l|c|c|}
\hline \multicolumn{1}{|c|}{ Variables } & Correlation coefficient value, $r$ & Significance level, $p$ \\
\hline Risk appetite "PSK" by A.M. Schubert & 0,634 & 0,01 \\
\hline Extraversion (Keirsey questionnaire) & 0,619 & 0,002 \\
\hline Feeling (Keirsey questionnaire) & 0,772 & 0,000 \\
\hline
\end{tabular}

Students with average risk appetites have an ISTJ psychological profile. This type is characterised by responsibility, reliability; duty, hierarchy, order are essential for this type; practical, open, everything goes according to plan; without nonsense and unnecessary inventions; ingenious, executive, integral nature.

Students of the third group with a low propensity to take risks have the ISFJ psychological profile. This type is characterised by sociability, attentiveness to the feelings of other people, good parenting; impatient with routine and monotonous activities; distinguished by the ability to distribute roles in the group.

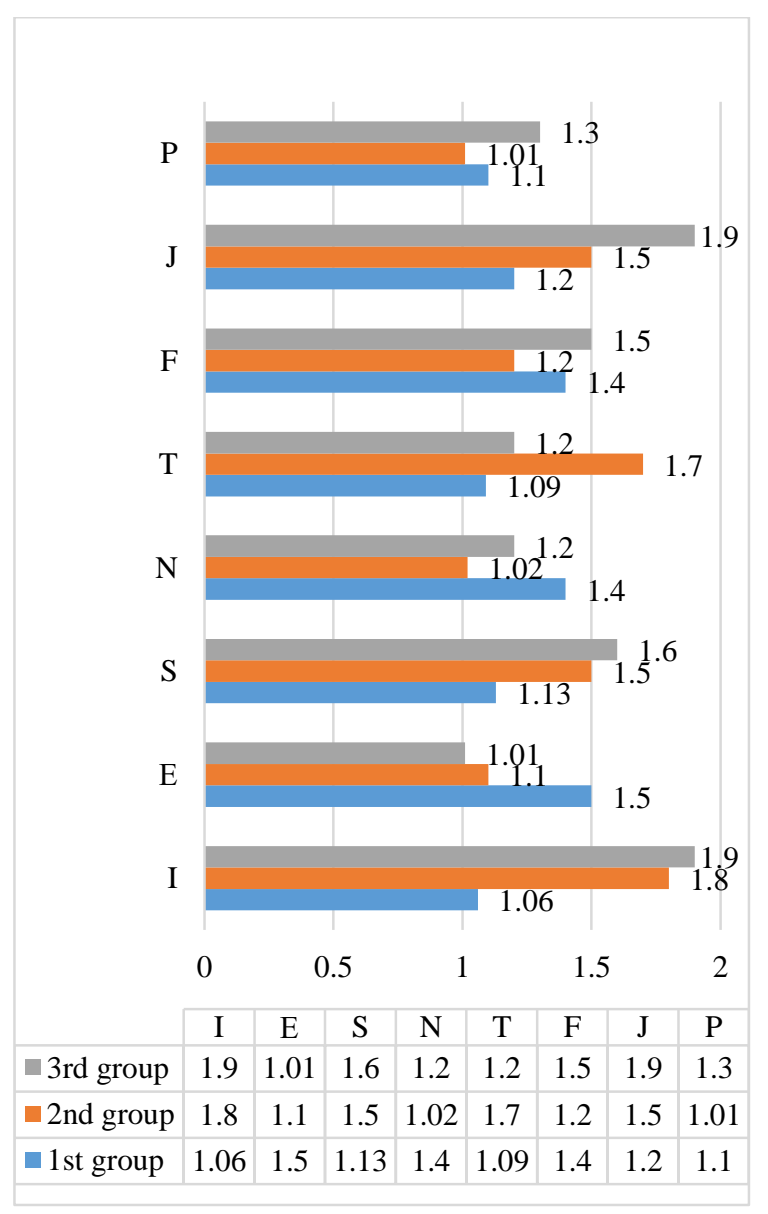

Figure 2 Average values of the level for personal characteristics in medical students by Keirsey method (compiled by the authors based on the results of the study).
To identify the structure of the relationship between personality traits and the risk appetite for medical students, a correlation analysis was carried out using the Spearman correlation criterion (table 1).

Because of the use of correlation analysis, multiple correlations were obtained between the factors under study.

There are positive correlations between high-risk appetite and extraversion (0.649). This means that as extraversion increases, the propensity to take risks increases.

There is a positive correlation between high-risk appetite and feeling (0.772). This means that as feeling increases, the propensity to take risks increases.

\section{CONCLUSIONS}

Thus, based on the study, it was found that the leading personality characteristics of students with a high propensity to take risks are extraversion, intuition, feeling, judging (ENFJ). Students with a high propensity to take risks will feel much more comfortable in stressful situations, in professions associated with constant stress; they are expressive, have a pronounced persistence and organisation. They have a more pronounced aspiration for success. The obtained research data can be used in the work of practical psychologists of educational institutions for career guidance activities for students graduating from a medical university.

\section{REFERENCES}

[1] M.T. Tsuang, M. Boor, J.A. Fleming, Psychiatric aspects of traffic accidents, American Journal of Psychiatry Vol. 42 (1985) 538-546.

[2] A.A. Shklyarova, The relationship of personality traits and adaptation of first-year students to higher education. Retrieved from: http://ekoncept.ru/2017/770235.htm

[3] A.V. Yanykhbash, Inclination to risk in the structure of personality traits. Retrieved from: 
https://cyberleninka.ru/article/n/sklonnost-k-riskuv-strukture-lichnostnyh-osobennostey

[4] E.Yu. Mandrikova, Choice of a Personality: Modern Approaches to Its Study, Scientific Notes of the Department of General Psychology, Lomonosov Moscow State University 2 (2006) 234-271.

[5] N. Kogan, M. Wallach, Risky shift phenomenon in small decision groups: a test of the informationexchange hypothesis, Journal of Experimental Social Psychology Vol. 3 (1967) 75-84.

[6] T.V. Kornilova, Psychology of risk and decision making: Textbook for universities, M.: Aspect Press, 2003, p. 286.

[7] N.V. Moskvina, Individual characteristics of volitional regulation (on the example of students of a sports university), Sports psychologist 3(21) (2010) 44-49.

[8] E.V. Chastoedova, M.S. Istomina, M.V. Zlokazova, The level of medical students' anxiety and risk appetite (gender aspects). Retrieved from: https://cyberleninka.ru/article/n/uroven-

trevozhnosti-i-sklonnosti-k-risku-u-studentovmeditsinskogo-vuza-gendernye-aspekty

[9] R.I. Mukhamadeev, I.G. Mukhamadeev, Research of the risk appetite level among students in the context of improving labour safety. Retrieved from: http://eduherald.ru/ru/article/view?id=12029

[10] V.P. Pugachev, Tests, business games, training in personnel management, Aspect Press, 2003, 285 p. 